REVISTA DE DERECHO UNED, NÚM. 10, 2012

\title{
DE LA PRIMERIDAD A LA PRIMARIEDAD EN LA TUTELA DE LOS DERECHOS. LA TUTELA A TRAVÉS DE LA TUTELA
}

\author{
Juan Manuel Goig Martínez \\ Profesor Titular de Derecho Constitucional. Departamento \\ de Derecho Político
}

Resumen: El Poder Judicial se ha convertido en un poder esencial en la actual conformación del Estado constitucional democrático, en especial en la defensa de los derechos constitucionales. La reforma de la regulación del recurso de amparo ha situado a los órganos jurisdiccionales en el centro de la tutela de los derechos, reconociendo una posición que ya estaba reconocida al elevar el constituyente español el derecho a la tutela judicial efectiva y la prohibición de indefensión, a la categoría de derecho fundamental

Abstract: The judiciary has become a power essential in the current formation of the democratic constitutional State, especially in the defense of constitutional rights. The reform of the regulation of the remedy of amparo has located to the courts in the centre for the protection of the rights, recognizing a position which was already recognized by raising the constituent Spanish the right to effective judicial protection and the prohibition of helplessness to the category of fundamental right.

Palabras clave: Constitución, Poder Judicial, derechos, recurso de amparo, tutela judicial, prohibición de indefensión.

Key words: Constitution, the judiciary, rights, resource protection, judicial protection, prohibition of helplessness

Sumario: I. La posición del Poder Judicial en el conjunto de poderes del Estado. La función tutelar del juez en materia de derechos y 
libertades.-II. El Tribunal Constitucional como garante primario de los derechos. La reforma del recurso de amparo.-III. La tutela efectiva de los derechos y libertades a través de la actuación jurisdiccional ordinaria. El juez protector de los derechos.-IV. La prohibición de indefensión como contenido principal de la tutela judicial.-V. Los mandatos derivados de la prohibición de indefensión.

\section{LA POSICIÓN DEL PODER JUDICIAL EN EL CONJUNTO DE PODERES DEL ESTADO. LA FUNCIÓN TUTELAR DEL JUEZ EN MATERIA DE DERECHOS Y LIBERTADES}

La función judicial que, sin duda ha sido la más débil en los inicios de la división de poderes, es hoy, en muchos aspectos, la más poderosa. El Poder judicial ocupa, desde el Siglo XVIII una posición única en el cuadro de poderes del Estado. De la concentración de poderes, incluido el judicial, en manos de una sola persona (el Rey), se ha pasado a una separación de poderes en la que el Poder Judicial ha asumido un papel protagonista como consecuencia de la conformación actual del Estado como Estado de partidos, en el que se observa cierta «confusión» entre legislativo y ejecutivo, que hace que el Parlamento y el Gobierno se hayan convertido en una suerte de subestructuras de las decisiones de los partidos políticos. En esta situación, el Poder Judicial se ha convertido en el eje fundamental del Estado de Derecho ${ }^{1}$.

El Estado Social y Democrático de Derecho implica, además del objeto social redistributivo, la concepción democrática del poder y la sumisión a las normas jurídicas. Esta afirmación había llevado a DE $\mathrm{OTTO}^{2}$ a defender la necesidad del establecimiento de «una fuerza que se preocupe de que, al menos, los valores superiores del Derecho y del orden que la Constitución ha establecido como fundamentales, permanezcan protegidos», fuerza que se sitúa en el juez. LOEWENSTEIN ${ }^{3}$, por su parte, sostenía que la independencia de los jueces, ejerciendo las funciones que se les han atribuido y su libertad frente a las posibles interferencias de los otros detentadores del poder, constituye la piedra final en el edificio del Estado democrático constitucional de Derecho.

${ }^{1}$ GARCÍA PELAYO, M., El Estado de Partidos, Alianza Ed. Madrid, 1986, págs. 114 y ss.

2 DE OTTO, I., Estudios sobre el Poder Judicial. Ministerio de Justicia, Madrid, 1989. Introducción.

3 LOEWENSTEIN, K., Teoría sobre la Constitución, Ariel, Barcelona, 1979. pág. 294. 
El Estado Democrático de Derecho ha propiciado la asignación específica de funciones a los detentadores de los distintos poderes, otorgando al Poder Legislativo la potestad de aprobar leyes y controlar al Gobierno; al Poder Ejecutivo la dirección de la vida política, interna y externa del país, y al Poder Judicial, la función de juzgar y hacer ejecutar lo juzgado en base a la ley establecida. Sin embargo, la misma naturaleza de la finalidad del Poder judicial le convierte en un órgano poderoso dentro del Estado, y lo sitúa en una especial posición de soledad respecto al resto de los poderes, pues se le encomienda la función de juzgar a éstos, con lo que se rebasa así la esfera de los gobernados, para abarcar también a los gobernantes.

Como ha indicado PIZZORUSSO, la posición constitucional del Poder Judicial se manifiesta y se justifica, como portador, en el proceso de creación-actuación del Derecho, de una influencia jurídicocultural válida para asegurar el respeto de los principios fundamentales de la Constitución y la continuidad del Derecho ${ }^{4}$, con lo que se superan las primeras apreciaciones limitadoras que MONTESQUIEU hiciera respecto al Poder Judicial ${ }^{5}$.

Si el Estado de Derecho supone la limitación del poder del Estado por el Derecho y la orientación del Estado a la protección y realización de las exigencias de libertad, igualdad y seguridad, el Poder Judicial, separado e independiente de los demás, que encuentra su límite en la ley y encargado de velar por la aplicación del Derecho en cuanto administrador de justicia, se convierte en uno de los pilares básicos para el sostenimiento del Estado de Derecho.

Frente a la inicial asepsia con que se configuraba, inicialmente, la actividad del juez, considerada una pura función mecánica en la aplicación de la ley, el desarrollo del Poder Judicial, fruto de su independencia y sumisión a la ley, lo ha convertido en uno de los intérpretes y hacedores del Derecho. Corresponde en exclusiva a jueces y magistrados la inteligencia, aplicación e interpretación de la legalidad ordinaria, así como la selección y análisis de la vigencia de la norma (STC 359/1993 de 29 de noviembre) y la unificación de la doctrina (STC 246/1993 de 19 de julio).

Así pues, es al juez ordinario a quien compete la interpretación de

${ }^{4}$ PIZZORUSSO, A., La organización de la Justicia en Italia, Torino, 1982. págs. 50 y ss.

5 Montesquieu lo define como «en quelque façon nul qu'est la bouche que prononce les paroles de la loi». es decir, como un poder que en cierto modo es nulo, pues se limita a ser la boca que pronuncia las palabras de la ley. Vid. MONTESQUIEU, CH DE S., De l'esprit des lois, Garnier, 1878. 
la legalidad ordinaria con la consiguiente asunción por parte de los Tribunales, incluso del Tribunal Constitucional de su decisión, de forma que no pueda éste controlar esta actuación más que cuando sea manifiestamente arbitraria o incurra en error patente y de ello se derive una conculcación de los derechos consagrados en la Constitución y susceptibles de amparo constitucional.

Junto a la consideración de jueces de la legalidad ordinaria, y al margen de la consideración del Tribunal Constitucional como máximo intérprete de la Constitución, los órganos judiciales son también, y primeramente, jueces de la Constitución y de los derechos fundamentales (STC 232/1993 de 12 de julio). La Constitución es una norma directamente aplicable que obliga a todos los poderes públicos, y el Tribunal Constitucional es el intérprete supremo, pero no el único, de la Constitución, por lo tanto, nuestros jueces están obligados a interpretarla, de forma que el juez ordinario actúa como juez de la constitucionalidad, hecho que el Tribunal Constitucional ha defendido desde sus primeras sentencias (STC 4/1981 de 2 de Febrero).

Además, los ordenamientos constitucionales han convertido a los tribunales ordinarios en garantes primarios de los derechos y libertades que las Constituciones reconocen a sus ciudadanos.

Se atribuye al Poder Judicial la protección de los derechos subjetivos y la resolución de las controversias que como consecuencia de su vulneración se producen, sin reducir esta función a los relativos a derechos de naturaleza exclusivamente privada, sino que, y muy especialmente, compete a los órganos judiciales la defensa de las libertades públicas.

El artículo 53 de la Constitución ha convertido a los órganos judiciales en auténticos protectores de los derechos en ella enunciados. Tras afirmar que los derechos y libertades reconocidos en el Capítulo II del Título I vinculan a todos los poderes públicos, establece que cualquier ciudadano podrá recabar la tutela de las libertades y derechos reconocidos en el artículo 14 y la Sección Primera de dicho Capítulo ante los tribunales ordinarios por un procedimiento basado en los principios de preferencia y sumariedad. Este procedimiento, ha llegado a ser considerado como el dispositivo de tutela de los derechos, acogidos al mismo, más eficaz de cuantos conoce nuestro ordenamiento ${ }^{6}$.

${ }^{6}$ AlZAGA VILlamiL, O., Derecho político español. Según la Constitución de 1978, Vol. I, Edersa, Madrid, 1996. pág. 385. 
Junto a estos derechos que gozan del más alto nivel de protección, la Constitución ha querido que en la medida en que los principios rectores de la política social y económica reconocidos en el Capítulo III del Título I, sean desarrollados por ley, puedan ser defendidos por la jurisdicción ordinaria, de acuerdo con las leyes que los desarrollan.

Esta atribución del Poder Judicial, como garante de los derechos y libertades coincide, en el caso español, con la elevación a la categoría de derecho fundamental, y por tanto especialmente protegido, del derecho a la tutela judicial efectiva, reconocido en el artículo 24, que hace del juez el órgano tutor que evite la indefensión ${ }^{7}$.

\section{EL TRIBUNAL CONSTITUCIONAL COMO GARANTE PRIMARIO DE LOS DERECHOS. LA REFORMA DEL RECURSO DE AMPARO}

El artículo 53.2 CE configura un procedimiento basado en los principios de preferencia y sumariedad, considerado por un importante sector de la doctrina como el primer instrumento de protección y restablecimiento de los derechos fundamentales y las libertades públicas.

Nuestra Constitución, en consonancia con otras Constituciones europeas, ha residenciado en el Tribunal Constitucional la defensa última de los derechos y libertades. El art. 53.2 CE encomienda, con carácter general, a los Tribunales ordinarios la tutela de los derechos y libertades fundamentales, especialmente a través de un procedimiento caracterizado por la preferencia y la sumariedad, lo que se ha dado en llamar el «amparo judicial ordinario» de los derechos fundamentales, mientras que al Tribunal Constitucional se le otorga a través del recurso de amparo «en su caso» (...), el «amparo constitucional» de dichos derechos y libertades. Dada la trascendencia de las libertades y los derechos fundamentales consagrados por la Constitución (arts. 14 a 30) se prevé en ella para su protección un doble mecanismo jurisdiccional escalonado, principal y general uno, que se atribuye a los Tribunales ordinarios, y extraordinario y subsidiario otro, que corresponde al Tribunal Constitucional. La Constitución, se refiere pues, a dos jurisdicciones diferentes: la del Poder Judicial que de forma exclusiva y excluyente tiene la potestad de juzgar y hacer ejecutar los juzgado en todo tipo de procesos (Título VI CE) y es,

7 SÁNCHEZ AGESTA, L., Sistema político de la Constitución española de 1978, $7^{\mathrm{a}}$ Ed. puesta al día por, ALZAGA VILLAMIL, O., Edersa. Madrid, 1994, págs. 380 y ss. 
por tanto, la común u ordinaria en la tutela de los derechos y libertades; y la del TC (Título IX CE) cuyo ámbito de actuación o de jurisdicción se limita a las garantías constitucionales, y entre ellos, el recurso de amparo utilizable «en su caso» para la protección de aquellos derechos cuando entienda el justiciable que no han sido reparados por la jurisdicción ordinaria (STC 113/1995, de 6 de julio).

El TC ha señalado en reiteradas ocasiones que nada que afecte al ejercicio de los derechos que la Constitución reconoce a los ciudadanos puede considerarse ajeno a él (STC 26/1981, de 17 de julio), convirtiéndose el recurso constitucional de amparo en un medio de superprotección de los derechos fundamentales ${ }^{8}$. De ello debemos deducir la necesidad de este recurso, necesidad que, además, se convierte en exigencia constitucional, puesto que, aunque en algunas ocasiones se ha llegado a pensar en sentido contrario -admitiéndose una amplia disponibilidad del legislador, con la consiguiente desconstitucionalización del art. 53.2 CE-, entendemos que la cláusula «en su caso» que contiene el art. 53.2 CE. no implica la posibilidad del legislador de crearlo o no. La propia Constitución considera el recurso de amparo un instrumento necesario, aunque lo hace «en los casos y formas que la ley establezca». Pero la importancia del recurso de amparo va más allá, puesto que a través de la resolución de los recursos de amparo y en virtud de la fuerza vinculante de sus decisiones y de los efectos jurídicos e ideológicos de la jurisprudencia constitucional, el TC no sólo ha contribuido decisivamente a generar, en los poderes públicos y en la sociedad una actitud de respeto hacia aquellos derechos y libertades, sino que también ha inyectado un revulsivo en la práctica administrativa y judicial ${ }^{9}$.

La regulación constitucional y legislativa y las características del recurso constitucional de amparo han configurado una de las competencias de mayor amplitud, complejidad y uso de todas las que tiene atribuidas el Tribunal Constitucional y para constatar este hecho no hay más que remitirse a las estadísticas sobre el volumen de recursos interpuestos ante el TC.

Este excesivo volumen de recursos, que ha llegado a colapsar la propia actividad del TC, ha provocado una temprana y continua producción científica en aras a intentar paliar las dificultades prácticas

8 ARAGÓN REYES, M., «El artículo 161 de la Constitución española» en ALZAGA VILLAMIL, O. (Dir) Comentarios a la Constitución de 1978, Tomo XII, Edersa-Cortes Generales, 1999, pág. 209.

9 SÁNCHEZ MORÓN, M., El recurso de amparo constitucional. Características y crisis, CEC, Madrid, 1987, pág. 13. 
del recurso constitucional de amparo, iniciada en la tensión doctrinal encabezada por los Profesores CRUZ VILLALÓN y DIEZ-PICAZO ${ }^{10}$, y continuada por otros muchos sectores doctrinales ${ }^{11}$.

El recurso de amparo no es un medio ordinario de protección de los derechos fundamentales y, en consecuencia, no cabe acudir directamente ante el Tribunal Constitucional sin que los órganos jurisdiccionales hayan tenido la oportunidad de reparar la lesión por los cauces que el ordenamiento jurídico ofrece, ya que en otro caso se producirían dos consecuencias no conformes con la Constitución: en primer lugar, la desnaturalización del recurso de amparo al perder su carácter subsidiario y pasar a la primera línea de defensa de los derechos fundamentales presuntamente vulnerados, y, en segundo lugar, y en correspondencia con lo anterior, una injustificada alteración de las funciones que respectivamente corresponden a los Tribunales ordinarios y a este Tribunal en materia de los derechos fundamentales con merma de la encomendada por la Constitución a los primeros (STC 216/2000, de 18 de septiembre).

El recurso de amparo es un remedio último y extraordinario que se reserva para aquellos casos en que el proceso ante los tribunales ordinarios haya resultado ineficaz. No es un medio de impugnación de las resoluciones de un órgano inferior, sino que es un auténtico proceso $^{12}$.No es una nueva instancia jurisdiccional, ni se configura como un recurso de casación, sino que es un instrumento procesal dotado de sustantividad propia. El recurso de amparo es un remedio subsidiario, puesto que ante la violación de los derechos fundamentales, los ciudadanos han de acudir con carácter previo a la jurisdicción ordinaria.

La finalidad esencial del recurso de amparo es la protección, en sede constitucional, de determinados derechos y libertades, cuando las vías ordinarias de protección han resultado insatisfactorias. Jun-

10 Vid. al respecto, CRUZ VILLALÓN, P., "El recurso de amparo constitucional: el juez y el legislador» en VVAA Los procesos constitucionales, CEC, Madrid, 1992; DÍEZ-PICAZO, L. M., «Dificultades prácticas y significado constitucional del recurso de amparo» en $R E D C$, n ${ }^{\circ} 40,1994$; CRUZ VILLALÓN, P., "Sobre el amparo», en $R E D C \mathrm{n}^{\circ} 41,1994$.

11 Vid., entre otros. PÉREZ TREMPS, P. (Coord)., La reforma del recurso de amparo, Tirant lo Blanc, Valencia, 2004. CARMONA CUENCA, E., La crisis del recurso de amparo: la protección de los derechos fundamentales entre el poder judicial y el Tribunal Constitucional, Universidad de Alcalá de Henares, 2005. FERNÁNDEZ SEGADO, F., "La reforma del régimen jurídico-procesal del recurso de amparo»-Revista Ius et Praxis-, año, 2008.

12 STC 11/1992, de 27 de enero. 
to a este designio, aparece también el de la defensa objetiva de la Constitución, sirviendo de este modo la acción de amparo a un fin que transciende lo singular. Para ello el TC actúa como un intérprete supremo, de manera que su interpretación de los preceptos constitucionales, es decir, la definición de la norma, se impone a todos los poderes públicos (STC 1/1981, de 26 de febrero).

Es decir, el recurso de amparo tiene un carácter esencialmente subjetivo que impide que se convierta en un proceso que se considere como una vía adecuada para efectuar juicios abstractos de inconstitucionalidad de normas o, en general, para garantizar en abstracto la correcta aplicación de los preceptos de la Constitución que recogen y garantizan derechos, aunque, cuando de la inadecuada interpretación de estos preceptos se derive, además, una violación a derechos o libertades, actúa defendiendo la Constitución de manera objetiva.

Debemos afirmar, sin embargo, que en la práctica, la mayoría de recursos de amparo que se plantean, lo es por actuaciones judiciales. Si tenemos en cuenta la cantidad de problemas y errores, meramente procesales, que surgen a lo largo de un juicio, el abogado que pretenda alargar un proceso, y convertir un procedimiento ordinario en un procedimiento constitucional, no tiene más que interponer un recurso de amparo por violación del artículo 24 de la Constitución, que en la mayoría de los casos son desestimados.

Este problema ha llevado a la doctrina a plantearse, desde los primeros momentos de vida del recurso de amparo, la posibilidad de que se establecieran medidas disuasorias, o la modificación legislativa, para permitir un trabajo más sosegado del TC, de manera que la defensa última de los derechos no alterara el normal funcionamiento de nuestro sistema de justicia constitucional.

Para ello, la LOTC ha sufrido diversas modificaciones tendentes a racionalizar, principalmente, el uso del recurso de amparo. Sin duda, la más importante, ha sido la reforma introducida en la LOTC por la Ley Orgánica 6/2007, de 24 de mayo, que exige verificar que la demanda de amparo cumple los requisitos establecidos en el art. 50.1 LOTC, que establece:

Art. 50.1. El recurso de amparo debe ser objeto de una decisión de admisión a trámite. La Sección, por unanimidad de sus miembros, acordará mediante providencia la admisión, en todo o en parte, del recurso solamente cuando concurran todos los siguientes requisitos: 46 y 49 .

a) Que la demanda cumpla con lo dispuesto en los artículos 41 a 
b) Que el contenido del recurso justifique una decisión sobre el fondo por parte del Tribunal Constitucional en razón de su especial trascendencia constitucional, que se apreciará atendiendo a su importancia para la interpretación de la Constitución, para su aplicación o para su general eficacia, y para la determinación del contenido y alcance de los derechos fundamentales.

La exposición de motivos de la citada Ley Orgánica 6/2007 destaca, entre las reformas que aborda, la nueva configuración del recurso de amparo y, singularmente, la de su trámite de admisión. En dicha exposición de motivos se llama la atención sobre que, si bien el sistema anterior a la reforma se basaba en la previsión de «causas de inadmisión tasadas», la reforma introduce un sistema en el que «el recurrente debe alegar y acreditar que el contenido del recurso justifica una decisión sobre el fondo por parte del Tribunal en razón de su especial trascendencia constitucional, dada su importancia para la interpretación, aplicación o general eficacia de la Constitución». Esta novedad supone, tal como también incide la exposición de motivos, una inversión del juicio de admisibilidad, ya que se pasa de comprobar la inexistencia de causas de inadmisión a la verificación de la existencia de una relevancia constitucional en el recurso de amparo formulado, por lo que el examen de admisión consistirá, materialmente, en la comprobación en las alegaciones del recurrente de la existencia de relevancia constitucional en el recurso.

Así pues, el elemento más novedoso o la «caracterización más distintiva» (ATC 188/2008, de 21 de julio, FJ 3) de esta nueva regulación del recurso de amparo, lo constituye el requisito sustantivo, o de fondo, de la «especial trascendencia constitucional» que impone el art. 50.1 b) LOTC para la admisión del recurso. En él se plasma la opción del legislador, en el ejercicio de la habilitación que constitucionalmente le confiere el art. 161.1 b) CE, en relación con su art. 53.2, por una nueva configuración del recurso de amparo, toda vez que, en principio, tras la reforma llevada a cabo, la mera lesión de un derecho fundamental o libertad pública tutelable en amparo ya no será por sí sola suficiente para admitir el recurso, pues es imprescindible, además, su «especial trascendencia constitucional», frente a la configuración por la que esencialmente se caracterizaba en su anterior regulación, en tanto que recurso orientado primordialmente a reparar las lesiones causadas en los derechos fundamentales y libertades públicas del demandante susceptibles de amparo. Así pues, para la admisión del recurso de amparo no es suficiente la mera lesión de un derecho fundamental o libertad pública del recurrente tutelable en amparo [arts. 53.2 y 161.1 b) CE y 41 LOTC], puesto que la lesión del 
derecho puede ser definida y reparada por el órgano judicial, como tutor primero -entendida en su acepción de quien actúa en primer lugar, que precede a otros en su actuación- sino que además es indispensable, en lo que ahora interesa, la especial trascendencia constitucional del recurso [art. 50.1 b) LOTC $]^{13}$.

La reforma de la regulación del recurso de amparo, implica, además de su racionalización, convertir a los tribunales ordinarios en los defensores primeros de los derechos y libertades, función que ha

13 El carácter notablemente abierto e indeterminado, tanto de la noción de «especial trascendencia constitucional», como de los criterios legalmente establecidos para su apreciación, confieren al TC un amplio margen decisorio para estimar cuándo el contenido de un recurso de amparo justifica una decisión sobre el fondo en razón de su especial trascendencia constitucional. En la interpretación del requisito del art. 50.1 b) LOTC, el TC considera que cabe apreciar que el contenido del recurso de amparo justifica una decisión sobre el fondo en razón de su especial trascendencia constitucional en los casos que a continuación se refieren, sin que la relación que se efectúa pueda ser entendida como un elenco definitivamente cerrado de casos en los que un recurso de amparo tiene especial trascendencia constitucional, pues a tal entendimiento se opone, lógicamente, el carácter dinámico del ejercicio de nuestra jurisdicción, en cuyo desempeño no puede descartarse a partir de la casuística que se presente la necesidad de perfilar o depurar conceptos, redefinir supuestos contemplados, añadir otros nuevos o excluir alguno inicialmente incluido: Tales casos serán los siguientes: a) el de un recurso que plantee un problema o una faceta de un derecho fundamental susceptible de amparo sobre el que no haya doctrina del Tribunal Constitucional, supuesto ya enunciado en la STC 70/2009, de 23 de marzo; b) o que dé ocasión al Tribunal Constitucional para aclarar o cambiar su doctrina, como consecuencia de un proceso de reflexión interna, como acontece en el caso que ahora nos ocupa, o por el surgimiento de nuevas realidades sociales o de cambios normativos relevantes para la configuración del contenido del derecho fundamental, o de un cambio en la doctrina de los órganos de garantía encargados de la interpretación de los tratados y acuerdos internacionales a los que se refiere el art. 10.2 CE; c) o cuando la vulneración del derecho fundamental que se denuncia provenga de la ley o de otra disposición de carácter general; d) o si la vulneración del derecho fundamental traiga causa de una reiterada interpretación jurisprudencial de la ley que el Tribunal Constitucional considere lesiva del derecho fundamental y crea necesario proclamar otra interpretación conforme a la Constitución; e) o bien cuando la doctrina del Tribunal Constitucional sobre el derecho fundamental que se alega en el recurso esté siendo incumplida de modo general y reiterado por la jurisdicción ordinaria, o existan resoluciones judiciales contradictorias sobre el derecho fundamental, ya sea interpretando de manera distinta la doctrina constitucional, ya sea aplicándola en unos casos y desconociéndola en otros; f) o en el caso de que un órgano judicial incurra en una negativa manifiesta del deber de acatamiento de la doctrina del Tribunal Constitucional (art. 5 de la Ley Orgánica del Poder Judicial: LOPJ); g) o, en fin, cuando el asunto suscitado, sin estar incluido en ninguno de los supuestos anteriores, trascienda del caso concreto porque plantee una cuestión jurídica de relevante y general repercusión social o económica o tenga unas consecuencias políticas generales, consecuencias que podrían concurrir, sobre todo, aunque no exclusivamente, en determinados amparos electorales o parlamentarios. (STC 155/2009, de 25 de junio). 
sido reconocida desde los primeros momentos de la vida democrática española.

Como recientemente ha indicado el TC, la exigencia de agotamiento de la vía judicial previa tiene por objeto preservar el carácter subsidiario del recurso de amparo, evitando que el acceso a esta jurisdicción constitucional se produzca per saltum, esto es, sin dar oportunidad a los órganos judiciales de pronunciarse y, en definitiva, remediar la lesión que luego se invoca como fundamento del recurso de amparo (STC 8/1993, de 18 de enero), pues son ellos quienes tienen encomendada en nuestro sistema constitucional la tutela general de los derechos y libertades (STC 61/1983; SSTC 85/1999, de 10 de mayo; y 71/2000, de 13 de marzo). Por consiguiente, el agotamiento de la vía judicial ordinaria se malogra cuando no se hace uso de los recursos que son razonablemente exigibles a la parte, y también cuando, aun haciendo valer los recursos exigibles, el modo de su utilización priva a los órganos judiciales de la efectiva posibilidad de reparar la vulneración del derecho fundamental; en efecto, en uno y otro caso se infringe el principio de subsidiariedad (SSTC 85/1999, de 10 de mayo; 110/2001, de 7 de marzo; y 214/2002, de 11 de noviembre).

En definitiva, la exigencia de agotar la vía judicial previa no es en modo alguno una formalidad cuya eficacia real pueda ser debilitada por una interpretación decididamente antiformalista del precepto que la contiene, sino que se trata de un elemento esencial en el sistema de articulación de la jurisdicción constitucional con la jurisdicción ordinaria, cuyo exacto cumplimiento resulta indispensable para preservar el ámbito que al Poder Judicial reserva la Constitución (art. 117.3 CE) y para no desnaturalizar tampoco la función jurisdiccional propia del Tribunal Constitucional como su intérprete supremo (art. 1 LOTC; SSTC 211/1999, de 29 de noviembre; 128/2002, de 3 de junio; y 214/2002, de 11 de noviembre). (STC 174/2011, de 7 de noviembre), y como tutor primario -en su acepción de principal o superior en orden o grado- de los derechos constitucionales

\section{LA TUTELA EFECTIVA DE LOS DERECHOS Y LIBERTADES A TRAVÉS DE LA ACTUACIÓN JURISDICCIONAL ORDINARIA}

Con el derecho a la tutela judicial se ha trasformado la acción, como institución procesal básica, en derecho a la jurisdicción. Se trata de asegurar que el proceso judicial cumpla las funciones para 
las que ha nacido. La facultad de recabar la tutela judicial quedó comprendida, en un principio, en el seno del propio derecho subjetivo material controvertido, y, tras la correspondiente evolución histórica, adquirió primero la naturaleza de derecho subjetivo autónomo -el derecho de acción-, para alcanzar la categoría de derecho fundamental -el derecho a la tutela judicial-. Con ello se pretende instar a los poderes públicos la resolución de un conflicto que no puede ser resuelto por los propios particulares de manera arbitraria o mediante el uso de la fuerza ${ }^{14}$.

No obstante, su configuración y contenido, determina la necesidad de superar la idea de que su ámbito es estrictamente procesal. El artículo $24 \mathrm{CE}$ tiene que ser enmarcado dentro de las coordenadas del Estado Social y democrático de Derecho y adquiere un protagonismo especial en el reparto de poderes, afectando de manera especial a las relaciones entre la jurisdicción ordinaria y la jurisdicción constitucional.

En virtud del art. $24 \mathrm{CE}$, los integrantes del Poder Judicial, se convierten en hacedores primeros de los derechos y libertades, en sus intérpretes y defensores primeros, de manera que el TC es el intérprete y defensor último, actuando sólo cuando la defensa ordinaria ha resultado inútil, y, en la actualidad, la cuestión tiene especial relevancia constitucional.

El derecho de los ciudadanos a acceder a los tribunales de justicia para obtener de ellos la resolución de los conflictos en los que se encuentran inmersos, ha sido consagrado en los modernos Estados de Derecho al máximo nivel normativo y se ha erigido en uno de los más preciados derechos de los ciudadanos, otorgando a los tribunales ordinarios una posición especial en la configuración actual de los poderes públicos.

La tutela efectiva supone que el accionante o recurrente sea oído y obtenga una decisión fundada en derecho, favorable o desfavorable. El derecho a la jurisdicción se concreta en un derecho a ser parte en un proceso y poder promover la actividad jurisdiccional, a fin de llegar a una decisión judicial sobre las pretensiones formuladas (STC 122/1984, de 14 de febrero).

El objeto de este derecho se concreta en obtener la tutela en el ejercicio de los derechos e intereses legítimos, lo que se produce en el

14 GARBERÍ LLOBREGAT, J., Constitución y Derecho Procesal. Los fundamentos constitucionales del Derecho Procesal, Civitas, Madrid, 2009, págs. 115-116. 
momento en que se consigue una resolución judicial definitiva que debe ser cumplida. El término «efectiva» que acompaña a la tutela no significa que el titular del derecho a la misma tenga que conseguir la satisfacción de los derechos que se invocan como incumplidos (STC 12/1981, de 10 de abril).

Una vez que el ciudadano ha accedido a la justicia, el derecho a la tutela judicial efectiva adquiere varios perfiles, todos ellos tendentes a garantizar su efectividad. Se trata de evitar la indefensión del justiciable; por consiguiente, incluye el derecho a obtener una decisión judicial fundada en Derecho y que decida sobre el fondo del asunto.

El derecho de acceso a la jurisdicción constituye el primer contenido lógico del derecho a la tutela judicial efectiva. Se trata del primer contenido, desde la perspectiva cronológica, que se concreta en el derecho a ser parte en el proceso y poder promover la acción jurisdiccional que desemboque en una decisión judicial sobre las pretensiones deducidas (STC 77/2002, de 8 de abril).

El Tribunal Constitucional, en una muy reiterada y ya consolidada doctrina, recogida en sus inicios en las SSTC 61/1983, de 11 de julio, y 13/1987, de 5 de febrero, y confirmada en la STC 248/2006, de 24 de julio, ha venido declarando que el derecho a la tutela judicial efectiva incluye el derecho a obtener de los órganos judiciales una respuesta razonada, motivada, fundada en Derecho y congruente con las pretensiones oportunamente deducidas por las partes, por cuanto la motivación de las resoluciones judiciales, aparte de venir impuesta en el art. 120.3 CE, es una exigencia derivada del art. 24.1 $\mathrm{CE}$ que permite conocer las razones de la decisión que aquéllas contienen y que posibilita su control mediante el sistema de los recursos (entre otras muchas, SSTC 163/2000, de 12 de junio; 187/2000, de 10 de julio; y 214/2000, de 18 de septiembre). La motivación debe contener una fundamentación en Derecho (STC 147/1999, de 4 de agosto).

El art. 24 CE impone a los órganos judiciales, la obligación de dictar una resolución fundada en Derecho que no puede considerarse cumplida con la mera emisión de una declaración de voluntad en un sentido u otro, sino que debe ser consecuencia de una exégesis racional del ordenamiento, y no fruto de la arbitrariedad (SSTC 61/1983, de 11 de julio; 5/1986, de 21 de enero; 78/1986, de 13 de junio; 116/1986, de 8 de octubre, y 75/1988, de 25 de abril). No basta, pues, con obtener una respuesta motivada, sino que, además, ésta ha tener contenido jurídico y no resultar arbitraria (por todas, SSTC 
22/1994, de 27 de enero; 324/1994, de 1 de diciembre; 24/1999, 8 de marzo; 10/2000, de 17 de enero, y 182/2011, de 21 de noviembre).

El precepto se instala, en un primer momento, en el instante anterior al proceso; es el derecho a la tutela efectiva de jueces y tribunales, garantizando el acceso al mismo, y asegurando que éste tendrá lugar. Posteriormente, incluye las denominadas garantías procesales, sin las cuales no existiría esa tutela efectiva, lo que pone de manifiesto el sentido global del artículo 24, que constitucionaliza la instrumentalización formal de un derecho fundamental, el derecho a la defensa jurídica de los demás derechos por medio del denominado «derecho a la jurisdicción».

El art. 24 de la Constitución, en sus dos epígrafes, previene dos supuestos íntimamente relacionados entre sí, pero que merecen un tratamiento diferenciado, ya que el segundo de ellos apunta preferentemente a las llamadas "garantías procesales»-así el derecho al Juez ordinario predeterminado por la Ley, asistencia letrada, información de la acusación, proceso público, utilización de los medios de prueba pertinentes y presunción de inocencia-, mientras que el primero, al proclamar el derecho a obtener la tutela efectiva de los Jueces y Tribunales en el ejercicio de los derechos e intereses legítimos previniendo que nunca pueda producirse indefensión, establece una garantía, previa al proceso, que lo asegura, cuando se dan las circunstancias requeridas al efecto. Dicho de otro modo, el art. 24.2 también asegura la «tutela efectiva», pero lo hace a través del correcto juego de los instrumentos procesales, mientras que el 24.1 asegura la tutela efectiva mediante el acceso mismo al proceso (STC 46/1982, de 12 de julio).

El art. 24 de la Constitución supone no sólo que todas las personas tienen derecho al acceso a los Tribunales para el ejercicio de sus derechos e intereses legítimos, sino también que dichas personas -todas las personas- tienen derecho a "obtener una tutela efectiva» de dichos Tribunales. Y es que, difícilmente existe tutela judicial si en las distintas fases del proceso no responde al principio de «proceso justo con todas la garantías».

Dentro de estas garantías constitucionales podemos distinguir entre aquellas que son requisito previo para que el proceso iniciado se desenvuelva eficazmente y otorgue una tutela eficaz (derecho al juez ordinario o derecho a la asistencia letrada),y aquellas otras que se van a producir a lo largo del proceso y que deben permitir, no sólo una decisión fundada en derecho, sino que esa resolución pueda ser cum- 
plida, y a través de su ejecución pueda ser satisfecho el interés legítimo tutelado.

El derecho a un proceso con todas las garantías no debe ser entendido en un sentido restrictivo. Son garantías las enumeradas expresamente en el propio texto constitucional, pero no sólo estas, puesto que el proceso judicial está sometido a unas reglas de obligado cumplimiento para los órganos jurisdiccionales. Muchas de estas reglas, contribuyen a hacer realidad la buena marcha del proceso y la prohibición constitucional de indefensión; otras están constitucionalizadas a lo largo del texto constitucional, en relación con otros derechos constitucionales, pero igualmente extensibles al proceso, como pueden ser el derecho a guardar silencio, o el derecho a no confesarse culpable, o el derecho fundamental a ser informado de la acusación, que encierra un contenido normativo complejo e implica la exigencia constitucional de que el acusado tenga conocimiento de los hechos para poder defenderse adecuadamente y de manera contradictoria (STC 107/2002, de 6 de mayo). Otras, han sido creadas por los Tribunales Internacionales en materia de derechos, como por ejemplo la exigencia de garantías procesales especiales para las personas incapaces ${ }^{15}$, que bien podrían extenderse a personas que se encuentran en situaciones de especial desprotección y que, en definitiva, contribuyen a dar efectividad al derecho a un juicio justo.

El derecho a la tutela judicial efectiva consagra el derecho que tienen todas las personas al acceso a los órganos judiciales en el ejercicio de sus derechos e intereses legítimos, a obtener de los mismos una resolución fundada en derecho, con arreglo a las normas de competencia y procedimiento legalmente establecidas, a interponer los recursos establecidos en las leyes y a la efectividad de las resoluciones judiciales firmes mediante la ejecución de las mismas.

Se trata, en consecuencia, de un derecho amplio, que en sus dos apartados contempla un número elevado de derechos, complementarios entre sí, pero, a la vez, dotados de sustantividad propia, que se convierte en elemento imprescindible de defensa del resto de derechos constitucionales. Ahora bien, como ha indicado el propio TC (STC 230/2002, de 9 de diciembre), los derechos que reconoce el art. $24 \mathrm{CE}$, en sus dos párrafos, no pueden interpretarse de forma tan amplia que supongan cobijo o salvaguardia de todas las formas procesales, de manera que toda vulneración que de ellas pueda producirse se convierta por sí sola en un problema de orden constitucional,

15 STEDH 78/2001, Apdo.60. 
siempre que no se impida el acceso a los tribunales y la defensa de los derechos e intereses legítimos.

El artículo $24 \mathrm{CE}$ no solamente reconoce el derecho de acceso a la jurisdicción y el derecho a un proceso justo con todas las garantías, que asegure la efectiva realización de los principios de igualdad de las partes y de contradicción; proceso justo, con todas las garantías, que impone a los órganos jurisdiccionales el deber positivo de evitar desequilibrios entre las posiciones procesales de las partes o limitaciones en la defensa, que puedan producir a alguna de ellas el resultado de indefensión, sino que también comprende el derecho a obtener una respuesta fundada en derecho.

El artículo 24.1 CE no ampara el acierto de las resoluciones judiciales; no comprende la reparación o rectificación de errores, ni de las injusticias cometidas en la aplicación e interpretación de las normas, cuyo control corresponde al propio sistema de recursos judiciales (STC 136/2002, de 3 de junio). «Lo que ampara el art. 24.1 CE es el derecho a obtener una respuesta a la pretensión procesal, motivada, razonable, y no manifiestamente errónea ni lesiva de otros derechos fundamentales, que sea congruente y fundada en derecho» (STC 99/2001, de 23 de abril).

Elemento decisivo en la resolución judicial, por cuando incide de manera especial en la tutela judicial efectiva, es la motivación de las resoluciones judiciales, regulada en el art. 120.3 de la CE, que se convierte en garantía esencial para el justiciable, puesto que a través de la motivación es posible que la decisión judicial sea consecuencia de la aplicación razonada del ordenamiento jurídico y no el fruto de la arbitrariedad (STC 6/2002, de 14 de enero). El TC ha manifestado que la motivación no exige un razonamiento exhaustivo y pormenorizado, sino que es suficiente que venga apoyada en razones que permitan conocer cuáles han sido los criterios jurídicos esenciales fundamentadores de la decisión (STC 158/2002, de 16 de septiembre), permitiendo facilitar el control de la actividad jurisdiccional de los tribunales superiores, mejorando la posibilidad de defensa de los ciudadanos mediante la interposición de los recursos pertinentes. La motivación de las resoluciones judiciales, cumple, de esta manera, una doble función: por un lado, dar a conocer las reflexiones que conducen al fallo, por otro, facilitar su control mediante el sistema de recursos judiciales.

Sin embargo, no basta una respuesta motivada, sino que la resolución no puede resultar arbitraria ni irracional, entendiendo que procede apreciar irracionabilidad cuando se parte de premisas ine- 
xistentes o patentemente erróneas, o se sigue un desarrollo argumental que incurre en quiebras lógicas de tal magnitud que las conclusiones alcanzadas no pueden considerarse basadas en ninguna de las razones aducidas (STC 227/ 2002, de 29 de diciembre), y debe de tener contenido jurídico.

El derecho a la tutela supone el acceso de todos ante los tribunales para hacer valer nuestras pretensiones, derechos e intereses. Requerimos al órgano judicial para que dicte una resolución, aunque no nos sea favorable, que decida sobre el fondo del asunto, que sea congruente con nuestras peticiones y que esté lo suficientemente motivada para que no se produzca indefensión. Pero de nada sirve obtener una resolución judicial si ésta no llega nunca a ser ejecutada. El derecho a la tutela no se agota con el acceso a los tribunales. Exige también que el fallo judicial se cumpla y que las partes sean puestas en su derecho y compensadas, si hubiera lugar a ello, por el daño sufrido.

Es doctrina consolidada del TC (STC 28/1989, de 6 de febrero) que la ejecución de las sentencias forma parte del derecho a la tutela judicial, pues de lo contrario, las decisiones judiciales y los derechos que en las mismas se reconozcan no serían sino meras declaraciones de intereses sin alcance práctico ni efectividad alguna.

Definido por el TC como derecho de conformación legal, de carácter prestacional, respecto del cual le legislador puede establecer límites al pleno acceso a la ejecución de sentencias siempre que los mismos sean razonables y proporcionados respecto a los fines que lícitamente puedan perseguirse en el marco de la CE (STC 176/2001, de 17 de septiembre), implica el derecho a que las resoluciones judiciales se ejecuten en sus propios términos y respecto a la firmeza de esas mismas resoluciones y a la intangibilidad de las situaciones jurídicas en ellas declaradas (STC 156/2002, de 23 de julio), sin perjuicio de las posibilidades que el propio ordenamiento reconoce para su revisión y modificación (STC 135/2001, de 18 de junio).

Mediante este derecho, se protege y garantiza la eficacia de cosa juzgada material tanto en su aspecto negativo o excluyente, como el sentido positivo o prejudicial, impidiendo que los tribunales puedan desconocer o contradecir las situaciones jurídicas declaradas o reconocidas en sentencias firmes (STC 15/2002, de 28 de enero). Al derecho de ejecución de las resoluciones judiciales le es de aplicación el principio de intangibilidad o invariabilidad del fallo, como consecuencia del principio de seguridad jurídica, proclamado en el art. 9.3 CE, y del derecho a la tutela judicial efectiva (STC 55/2002, de 11 de marzo). 


\section{LA PROHIBICIÓN DE INDEFENSIÓN COMO CONTENIDO PRINCIPAL DE LA TUTELA JUDICIAL}

El art. 24.1 CE. constituye un precepto de contenido complejo, dentro del cual, el derecho a la tutela judicial efectiva, supone, en su vertiente positiva, el acceso al proceso y el uso de los instrumentos que el propio proceso aporta para la defensa de los intereses propios, pero cuya vertiente negativa convierte a la prohibición de indefensión en el límite más importante (STC 6/1990, de 18 de enero).

El derecho a la tutela judicial efectiva se encuentra estrechamente unido a la interdicción de indefensión, puesto que la tutela efectiva de los tribunales comporta la prohibición de indefensión como una exigencia, hasta el punto de que la indefensión deja sin contenido el derecho a la jurisdicción y constituye la tacha más grave de la que puede adolecer la tutela judicial, no sólo para que sea eficaz, sino para que pueda ser considerada como tutela judicial en sentido mínimo (STC 105/1995, de 3 de julio).

Nos encontramos ante uno de los principios que contribuye a la clarificación del Estado como Social y democrático de Derecho. El derecho a la justicia permite, en cuanto portadores de unos derechos, la posibilidad de acudir ante los tribunales para hacer efectivos esos derechos cuando nos sean lesionados, sin que, en ningún momento, el proceso pueda llegar a su fin a costa del derecho a la defensa de las partes ${ }^{16}$.

Aunque en los primeros pronunciamientos, el TC adoptó una concepción de indefensión tan amplia, genérica e indeterminada, que la identificaba con cualquier afectación de los derechos y garantías establecidas en el total del art. $24 \mathrm{CE}$, entendiendo que la indefensión comprendía todas las demás violaciones de derechos constitucionales que pueden colocarse en el marco del artículo 24 (STC 48/1984, de 4 de abril), hoy no es posible aceptarla en este sentido, porque equivaldría considerar la indefensión como un cajón de sastre en el que tendrían cabida todas las vulneraciones, incluidas todas las procesales.

La indefensión proscrita por el último inciso del art. $24 \mathrm{CE}$ es la que nace como consecuencia de una ilegítima privación o limitación de los medios de defensa producida en el seno de un proceso o de cualquiera de sus fases e incidentes, que acarrea al justiciable, sin que

16 ALZAGA VILLAMIL, O. y GOIG MARTíNEZ, J. M., «La prohibición de indefensión. El derecho a la defensa», en Boletín del Ilustre Colegio de Abogados de Madrid, $\mathrm{n}^{\circ} 17$, marzo 2001, págs. 12 y 13. 
le sea imputable, un perjuicio definitivo en sus derechos e intereses sustantivos ${ }^{17}$. La indefensión constitucionalmente prohibida -indefensión con relevancia constitucional- es aquella en la que a través de la necesaria, que no suficiente, trasgresión de los requisitos procesales con función de garantía, lleva a la disminución efectiva de las posibilidades de defensa de los intereses que nos son propios, debiendo ser algo real, efectivo y actual y nunca potencial y abstracto (STC 88/1999, de 26 de mayo).

Si como ha indicado el TC (STC 145/1990, de 1 de octubre, y otras), la indefensión tiene lugar cuando se priva al justiciable de alguno de los instrumentos que el ordenamiento pone a su alcance para la defensa de sus derechos con el consiguiente perjuicio real y efectivo para los intereses del afectado, para que concurra, deben darse como requisitos: a) la vulneración de una garantía procesal; b) la privación o limitación del derecho a la defensa; c) la imputabilidad al órgano judicial, y d) la incidencia en el fallo.

El derecho de defensa, con la consiguiente prohibición de indefensión es un elemento nuclear en la configuración del proceso penal del Estado de Derecho como un proceso con todas las garantías. No es posible construir un proceso justo si se elimina el derecho de defensa, de forma que las posibles restricciones deben estar especialmente justificadas.

En el artículo 24, el derecho a la defensa aparece junto a otros derechos que, aunque distintos e independientes entre sí, constituyen una batería de garantías orientadas a asegurar la eficacia real de uno de ellos: el derecho a un proceso con garantías, a un proceso equitativo, en términos del $\mathrm{CEDH}^{18}$; en definitiva, a un proceso justo, sin indefensión ${ }^{19}$. De forma que la pretensión legítima del Estado en

17 DÍEZ-PICAZO JIMÉNEZ, I., «Art. 24 CE. Garantías procesales», en Comentarios a la Constitución española de 1978, ALZAGA VILLAMIL, O. (Dir.), Tomo III, EdersaCortes Generales, Madrid, 1996, pág. 49.

18 En relación con el concepto y contenido de «juicio justo» puede verse la doctrina del Tribunal Europeo de Derechos Humanos en relación con la cuestión suscitada, inicialmente recogida en su Sentencia de 26 de mayo de 1988 -caso Ekbatani contra Suecia y consolidada posteriormente en pronunciamientos más recientes (SSTEDH de 8 de febrero de 2000 -caso Cooke contra Austria y caso Stefanelli contra San Marino-; 27 de junio de 2000 -caso Constantinescu contra Rumania-; y 25 de julio de 2000 -caso Tierce y otros contra San Marino-).

19 El Tribunal de Justicia de las Comunidades Europeas ha señalado en la Sentencia (Gran Sala) de 14 de setiembre de 2010, (Caso Azko y Akcros/Comisión) que cita otras anteriores en el mismo sentido, que»...el respeto del derecho de defensa en todo procedimiento que pueda dar lugar a sanciones, en particular a multas o a multas coercitivas, constituye un principio fundamental del Derecho de la Unión...». 
cuanto a la persecución y sanción de las conductas delictivas, solo debe ser satisfecha dentro de los límites impuestos al ejercicio del poder por los derechos que corresponden a los ciudadanos en un Estado de derecho. «Nadie discute seriamente en este marco que la búsqueda de la verdad, incluso suponiendo que se alcance, no justifica el empleo de cualquier medio. La justicia obtenida a cualquier precio termina no siendo Justicia ${ }^{20}$.

Como recientemente recuerda la STC 25/2011, de 14 de marzo, «la indefensión es una noción material que se caracteriza por suponer una privación o minoración sustancial del derecho de defensa; un menoscabo sensible de los principios de contradicción y de igualdad de las partes que impide o dificulta gravemente a una de ellas la posibilidad de alegar y acreditar en el proceso su propio derecho, o de replicar dialécticamente la posición contraria en igualdad de condiciones con las demás partes procesales. Por otro lado, para que la indefensión alcance la dimensión constitucional que le atribuye el art. $24 \mathrm{CE}$, se requiere que los órganos judiciales hayan impedido u obstaculizado en el proceso el derecho de las partes a ejercitar su facultad de alegar y justificar sus pretensiones, esto es, que la indefensión sea causada por la incorrecta actuación del órgano jurisdiccional (SSTC 109/1985, de 8 de octubre; 116/1995, de 17 de julio; 107/1999, de 14 de junio; 114/2000, de 5 de mayo; 237/2001, de 18 de diciembre, entre otras muchas)» (STC 25/2011, FJ 7, citando la 62/2009, de 9 de marzo).

Por ello, el contenido de la indefensión con relevancia constitucional queda circunscrito a los casos en que la misma sea imputable a actos $u$ omisiones de los órganos judiciales y que tenga su origen inmediato y directo en tales actos u omisiones; esto es, que sea causada por la incorrecta actuación del órgano jurisdiccional, estando excluida del ámbito protector del art. $24 \mathrm{CE}$ la indefensión debida a la pasividad, desinterés, negligencia, error técnico o impericia de la parte o de los profesionales que la representen o defiendan (por todas, SSTC 109/2002, de 6 de mayo; 141/2005, de 6 de junio; o 160/2009, de 29 de junio). Además «para que pueda estimarse una indefensión con relevancia constitucional, que sitúe al interesado al margen de toda posibilidad de alegar y defender en el proceso sus derechos, no basta con una vulneración meramente formal, sino que es necesario que de esa infracción formal se derive un efecto material de indefensión, con real menoscabo del derecho de defensa y con el

${ }^{20}$ STS 79/2012, de 9 de febrero, Sala de lo Penal. 
consiguiente perjuicio real y efectivo para los intereses del afectado» (SSTC 185/2003, de 27 de octubre; 164/2005, de 20 de junio; y 25/2011, de 14 de marzo).

El contenido de la prohibición de indefensión, o del derecho a la defensa, se manifiesta en todos los momentos procesales. Si el proceso se entiende como una oposición o contradicción entre pretensiones que un órgano judicial imparcial resuelve y las partes han de tener igualdad de armas con las que alegar y probar lo que es pertinente al objeto discutido y conveniente a sus intereses ${ }^{21}$, los principios de contradicción, de igualdad procesal y los derechos de alegación y prueba constituyen elemento esencial del contenido de la prohibición de indefensión. Pero también forman parte del contenido de esta prohibición, la congruencia y motivación de la sentencia, y el derecho al recurso y la prohibición de reformatio in pejus, como elemento de respeto a la seguridad jurídica.

\section{LOS MANDATOS DERIVADOS DE LA PROHIBICIÓN DE INDEFENSIÓN}

A pesar de que el contenido del art. 24 parece implicar un amplio abanico de derechos, la mayor parte de ellos dotados de entidad propia, y dirigidos a favorecer que la defensa de los derechos e intereses legítimos ante los tribunales sea efectiva, estos derechos constitucionalizados pasan a integrar el contenido del derecho a la defensa, constituyendo materializaciones concretas del derecho a la defensa y de la prohibición constitucional de indefensión ${ }^{22}$.

En un orden lógico y cronológico, del derecho a obtener la tutela judicial efectiva de los Jueces y Tribunales, que reconoce el art. 24.1 $\mathrm{CE}$, es el acceso a la jurisdicción, que se concreta en el derecho a ser parte en un proceso, para promover la actividad jurisdiccional que desemboque en una decisión judicial sobre las pretensiones deducidas (STC 220/1993, de 30 de junio). No se trata, sin embargo, de un derecho de libertad, ejercitable sin más y directamente a partir de la Constitución, ni tampoco de un derecho absoluto e incondicionado a la prestación jurisdiccional, sino de un derecho a obtenerla por los cauces procesales existentes y con sujeción a una concreta ordenación legal.

21 STS, Sala de lo Penal, de 28 de febrero de 1995.

22 ALZAGA VILLAMIL, O. y GOIG MARTíNEZ, J. M., "La prohibición de indefensión...», op. cit., pág. 35. 
La prohibición de indefensión implica un mandato y una obligación para los poderes públicos. Como ha indicado el TC (STC 48/1984, de 4 de abril), en el contexto del art. 24, la indefensión se caracteriza por suponer una privación o una limitación del derecho a la defensa que, si se produce por vía legislativa, sobrepasa el contenido esencial de los derechos prevenido en el art. $53 \mathrm{CE}$, y si se produce en virtud de concretos actos de los órganos jurisdiccionales entraña una mengua del derecho de intervenir en el proceso y del derecho de alegar y probar lo alegado. Se establecen, por consiguiente, una serie de mandatos, que también se extienden al Poder Ejecutivo.

El derecho a la tutela judicial efectiva, y la correspondiente prohibición de indefensión, es un derecho de configuración legal y un derecho de prestación..

En cuanto derecho de configuración legal, el legislador, dentro de su ámbito de atribuciones, puede establecer límites al pleno acceso a la jurisdicción. Nos hallamos, además, ante un derecho de prestación que solo puede ser reclamado de Jueces y Tribunales ordinarios integrantes del Poder Judicial, y dispensado en el ejercicio de la potestad jurisdiccional en todo tipo de procesos, juzgando y haciendo ejecutar lo juzgado (STC 205/1990, de 13 de diciembre), cuya naturaleza viene también caracterizada por se un derecho sustantivo, un auténtico derecho fundamental que adquiere significado propio con independencia de cual sea el derecho material que se sustancia en el proceso correspondiente, y no un derecho instrumental, o garantía constitucional de protección de derechos y libertades.

Su propia naturaleza, como derecho de configuración legal, como derecho prestacional, y como derecho sustantivo, impone varios mandatos, a los poderes públicos -a todos los poderes públicos-, que tienen que ver, de manera especial, con los propios derechos y libertades.

Los derechos humanos suponen la concreción de las exigencias derivadas de la dignidad, la libertad y la igualdad, y su reconocimiento, proclamación y tutela constituyen un elemento necesario a la propia definición estatal como Estado social y democrático de Derecho, lo que es especialmente importante en el constitucionalismo actual, y más concretamente, en nuestro modelo constitucional. Los derechos, en su acepción subjetiva, se mantienen y manifiestan como garantías de la libertad del individuo.

Los derechos fundamentales y las libertades públicas son derechos individuales que tienen al individuo como sujeto y al Estado por su- 
jeto pasivo en la medida que tienden a reconocer y proteger ámbitos de libertades o prestaciones que los Poderes Públicos deben otorgar o facilitar aquellos. Se deduce así, sin especial dificultad, del art. 10.1 $\mathrm{CE}$, que, en su apartado $1^{\circ}$ vincula los derechos inviolables con la dignidad humana y con el desarrollo de la personalidad y, en su apartado $2^{\circ}$, los conecta con los llamados derechos humanos, objeto de la Declaración Universal y de diferentes Tratados y Acuerdos Internacionales ratificados por España. (STC 64/1988, de 12 de abril).

Pero junto a esta dimensión subjetiva, los derechos también despliegan una dimensión objetiva a partir de la cual su contenido deberá de ponerse a disposición de la consecución de los fines y valores constitucionalmente proclamados.

Los derechos fundamentales son los componentes estructurales básicos, tanto del conjunto del orden jurídico objetivo como de cada una de las ramas que lo integran, en razón de que son la expresión jurídica de un sistema de valores que, por decisión del constituyente, han de informar el conjunto de la organización jurídica y política; son, como dice el artículo $10.1 \mathrm{CE}$, el fundamento del orden político y la paz social». «Los derechos y libertades fundamentales -de acuerdo con lo preceptuado en la CE en sus artículos 1.1 ; 9.2; 10.1 y $53-$ son elementos del ordenamiento, están contenidos en normas jurídicas objetivas, que forman parte de un sistema axiológico positivizado por la Constitución, y constituyen los fundamentos materiales del ordenamiento jurídico entero (STC 18/1981, de 8 de junio. STC 53/1985, de 11 de abril).

En primer lugar, los derechos fundamentales son derechos subjetivos, derechos de los ciudadanos no sólo en cuanto derechos de los ciudadanos en sentido estricto, sino en cuanto garantizan un estatus jurídico o la libertad en un ámbito de la existencia. Pero al propio tiempo, son elementos esenciales de un ordenamiento objetivo de la comunidad nacional, en cuanto ésta se configura como marco de una convivencia humana justa y pacífica plasmada históricamente en el Estado de derecho y, más tarde, en el Estado social de Derecho o el Estado social y democrático de Derecho, según la fórmula de nuestra Constitución. Esta doble naturaleza de los derechos fundamentales, se recoge en el art. 10.1 CE. Y una consecuencia básica de la derivación de los derechos y de la posición central que ocupan en el orden jurídico-político es la obligación que impone a los poderes públicos de dispensarles respeto absoluto.

Como ha indicado el Tribunal Constitucional (STC 53/1985, de 11 de abril), de la obligación de sometimiento de todos los poderes pú- 
blicos a la Constitución se deduce no solamente la obligación negativa del Estado de no lesionar la esfera individual o institucional protegida por los derechos fundamentales, sino también la obligación positiva de contribuir a la efectividad de tales derechos y de los valores que representan. Ello, obliga, especialmente a todos los poderes públicos.

De la posición de supremacía de la Constitución (art. 9.1CE) y la sujeción de los poderes públicos y los ciudadanos a ella, y al resto del ordenamiento jurídico, y la dimensión jurídica capital de los derechos y libertades como fundamentadores de la comunidad política (art. 10.1 CE) se derivan una serie de consecuencias jurídicas y unos mandatos a los poderes públicos, un deber positivo de dar efectividad a tales derechos y libertades (art. 9.2 CE). La Constitución, lejos de ser un mero catálogo de principios de no inmediata vinculación y de no inmediato cumplimiento hasta que sean objeto de desarrollo, es una norma jurídica, la Norma Suprema de nuestro ordenamiento jurídico a la que están sometidos los ciudadanos y los poderes públicos a través de una vinculación inmediata (STC 16/1982, de 28 de abril).

Y es que como ha indicado el TC, la sujeción de los poderes públicos a la Constitución también implica, por supuesto, la sujeción a los derechos y libertades por ella reconocidas, y, por consiguiente, si los derechos y libertades son los componentes estructurales básicos, tanto del conjunto del orden jurídico objetivo, como de cada una de las ramas que lo integran, puesto que son la expresión jurídica de un sistema de valores que, por decisión del constituyente, ha de informar el conjunto de la organización jurídica y política -son, como afirma el artículo 10.1, el fundamento del orden político y de la paz social-, de la significación y finalidades de los derechos dentro del orden constitucional, se desprende que la garantía de su vigencia no puede limitarse a la posibilidad del ejercicio de pretensiones por parte de los individuos, como que ha de ser asumida, también, por el Estado (STC 9/1981, de 31 de marzo).

Aun en la hipótesis de que un derecho constitucional requiera una «interpositio legislatoris» para su desarrollo y plena eficacia, nuestra jurisprudencia niega que su reconocimiento por la Constitución no tenga otra consecuencia que la de establecer un mandato dirigido al legislador sin virtualidad para amparar por sí mismo pretensiones individuales, de modo que sólo sea exigible cuando el legislador lo haya desarrollado. Los derechos y libertades fundamentales vinculan a todos los poderes públicos, y son origen inmediato de derechos y obligaciones, y no meros principios programáticos. Este 
principio general de aplicación inmediata no sufre más excepciones que las que imponga la propia Constitución, expresamente o bien por la naturaleza misma de la norma (STC 254/1993, de 20 de julio).

El primer mandato que impone la prohibición de indefensión, lo es respecto al Poder Legislativo.

En cuanto derecho de configuración legal es conformado por las normas legales, que determinan su alcance y contenido, y establecen los presupuestos y requisitos para su ejercicio, las cuales pueden establecer límites al pleno acceso a la jurisdicción, siempre que obedezcan a razonables finalidades de protección de bienes e intereses constitucionalmente protegidos (SSTC 140/1993, de 19 de abril; 12/1998, de 15 de enero, entre otras). De este modo el derecho a la tutela judicial efectiva puede verse conculcado por aquellas normas que impongan condiciones impeditivas u obstaculizadoras del acceso a la jurisdicción, siempre que los obstáculos legales sean innecesarios y excesivos y carezcan de razonabilidad y proporcionalidad respecto de los fines que lícitamente puede perseguir el legislador en el marco de la Constitución (SSTC 4/1988, de 12 de enero; 141/1988, de 29 de junio; 311/2000, de 18 de diciembre).

En el ámbito de los derechos fundamentales, como ha indicado DE OTTO, el legislador se halla ante un poder jurídico definido que no puede alterar en su contenido ${ }^{23}$, al menos en su contenido esencial, de manera que al concretizar el derecho, le está vedado actuar con eficacia constructiva. El legislador está vinculado a los derechos fundamentales, y no puede establecer la delimitación constitucional abstracta del objeto, contenido, funciones y límites de los derechos fundamentales, ya la configuración de sus elementos estructurales es función del poder constituyente. El legislador no puede decidir libremente sobre los derechos y libertades, sino que debe adecuarse al contenido constitucionalmente establecido.

Se trata de la imposición definitiva del principio de constitucionalidad, entendido como vinculación a la Constitución de todos los poderes públicos, sobre el legislador, de manera que la Constitución prefigura, y el legislador configura, en concordancia con la prefiguración previa.

Los poderes públicos, también el judicial, están sujetos a la Cons-

${ }^{23}$ DE OTTO, I., «La regulación del ejercicio de los derechos fundamentales. La garantía de su contenido esencial en el art. 53.1 de la Constitución», en Derechos fundamentales y Constitución, DE OTRO, I. y MARTÍN RETORTILLO, L. (eds), Madrid, 1988, pág. 155. 
titución y al resto del ordenamiento jurídico (artículo 9.1 CE); y el artículo 117.1 de la misma Constitución, somete a los jueces solamente al imperio de la ley. El monopolio de la jurisdicción y la facultad exclusiva de resolver los conflictos que se le presenten mediante la aplicación de la Ley, en un poder independiente que encuentra su límite en la aplicación del Ordenamiento Jurídico, resolviendo de manera vinculante y definitiva el asunto enjuiciado» (STS 238/2001, de 18 de diciembre).

La segunda vinculación, por consiguiente, de la prohibición de indefensión, lo es respecto a jueces y tribunales, integrantes del Poder Judicial.

La excepcional importancia de la función jurisdiccional que indicábamos al inicio de este estudio, especialmente en su faceta de defensor primero de los derechos -junto a la propia importancia que el derecho a la tutela judicial ha adquirido en el Estado de Derecho- nos podría llevar a la consideración del juez como "señor del derecho», puesto que en la actividad jurisdiccional se dan cita las dimensiones del Derecho (ley, derechos y justicia), y ello le llevaría a ser considerado por encima del legislador en creación jurídica, debido a la profunda conexión entre derechos fundamentales y justicia, sobre todo cuando se trata de derechos que por su propio carácter se orientan esencialmente a la consecución de la propia justicia, con lo que se crearía una situación definida como «de Estado de Derecho orientado a la Constitución y decidido por la jurisdicción ${ }^{24}$. Sin embargo, a pesar de la importancia que los integrantes del Poder Judicial han adquirido en nuestros días, el órganos jurisdiccionales no son los señores del derecho sino los garantes de la complejidad estructural del Derecho en el Estado Constitucional ${ }^{25}$.

La vulneración del derecho a la tutela judicial, no solo puede provenir del legislador cuando lo regula, sino que el Poder Judicial puede producir lesión al derecho mediante su actuación interpretativa y aplicadora.

La tutela judicial efectiva no incluye un pretendido derecho al acierto judicial en la selección, interpretación y aplicación de las disposiciones legales, salvo que con ellas se afecte al contenido de otros derechos fundamentales distintos al de tutela judicial efectiva (SSTC

${ }^{24}$ Vid. LÓPEZ PINA, A., «Tareas del Estado y el lugar de la ley», en Democracia representativa y parlamentarismo, LÓPEZ PINA, A. (ed.), Madrid, 1994.

${ }_{25}$ Vid. ZAGREBELSKY, G., EL DERECHO DÚCTIL. LEY, DERECHOS JUSTICIA, $2^{\mathrm{a}}$ ed. Madrid, 1997. 
256/2000, de 30 de octubre; 82/2001, de 26 de marzo). Pero la fundamentación en Derecho sí conlleva la garantía de que la decisión no sea consecuencia de una aplicación arbitraria de la legalidad, no resulte manifiestamente irrazonada o irrazonable, o incurra en un error patente, ya que, en tal caso, la aplicación de la legalidad sería tan sólo una mera apariencia (SSTC 147/1999, de 4 de agosto; 25/2000, de 31 de enero; 87/2000, de 27 de marzo; 82/2001, de 26 de marzo; 221/2001, de 31 de octubre; 55/2003, de 24 de marzo; 213/2003, de 1 de diciembre).

Puede verse conculcado el derecho de acceso a la tutela por aquellas interpretaciones de las normas que son manifiestamente erróneas, irrazonables o basadas en criterios que por su rigorismo, formalismo excesivo o cualquier otra razón, que revele una clara desproporción entre los fines que aquella causa preserva y los intereses que se sacrifican, de forma que la negación de la concurrencia del presupuesto o requisito en cuestión sea arbitraria o irrazonable (SSTC 35/1999, de 22 de marzo; 311/2000, de 18 de diciembre).

Asimismo es reiterada doctrina constitucional respecto del derecho de acceso a la jurisdicción que la interpretación de las normas procesales, y más en concreto el control de la concurrencia de los presupuestos que condicionan la válida constitución del proceso, son, en principio, operaciones que no trascienden el ámbito de la legalidad ordinaria, que competen a los órganos judiciales en el ejercicio de la función jurisdiccional que les es propia ex art. 117.3 CE, no siendo función del Tribunal Constitucional examinar la interpretación de la legalidad hecha por los órganos judiciales, salvo que por manifiestamente arbitraria, claramente errónea, o por no satisfacer las exigencias de proporcionalidad, inherentes a la restricción de todo derecho fundamental, implique por sí misma una lesión del derecho a la tutela judicial efectiva (SSTC 140/1987, de 23 de julio; 132/1992, de 28 de septiembre; 138/1995, de 25 de septiembre; 88/1997, de 5 de mayo; 236/1998, de 14 de diciembre; 165/1999, de 27 de septiembre; 301/2000, de 11 de diciembre; 311/2000, de 18 de diciembre. Descendiendo de lo general a lo particular, en el marco de la doctrina expuesta el Tribunal Constitucional ha declarado que no es de su competencia entrar a considerar con carácter general,un problema de estricta legalidad ordinaria, que incumbe resolver a los órganos jurisdiccionales (STC 301/2000, de 11 de diciembre; AATC 17/1990, de 15 de enero; 48/1996, de 26 de febrero). (STC 124/2002)

El ejercicio de la potestad jurisdiccional corresponde exclusivamente a los Juzgados y Tribunales (art. 117.3 C.E.), pero, como es ob- 
vio, no a cualquiera de ellos en cualquier caso, sino en cada uno de éstos a aquel órgano judicial que resulte predeterminado por las leyes «según las normas de competencia y procedimiento que las mismas establezcan» (art. 117.3 C.E.). La interpretación sistemática entre el art. 24.2 y el 117.3, de la Constitución, pone de manifiesto que la garantía de la independencia e imparcialidad de los Jueces, radica en la Ley $^{26}$. Según la STC 47/1983, de 31 de mayo, el derecho constitucional al Juez ordinario predeterminado por la ley, consagrado por el art. 24.2 de la Constitución, exige, en primer término, que el órgano judicial haya sido creado previamente por la norma jurídica, que ésta le haya investido de jurisdicción y competencia con anterioridad al hecho motivador de la actuación o proceso judicial y que su régimen orgánico y procesal no permita calificarle de órgano especial o excepcional.

El derecho al Juez ordinario predeterminado por la ley y a un proceso con todas las garantías -entre ellas, la independencia e imparcialidad del juzgador- es una garantía característica del proceso judicial. Dentro del haz de garantías que conforman el derecho al proceso debido, también se integra el derecho a la asistencia de Letrado reconocido en el art. 24.2 CE. Se trata de un derecho instrumental que trata de asegurar la efectiva realización de los principios de igualdad y contradicción entre las partes, por los que debe de velar el órgano jurisdiccional, y en los supuestos en que la ley exige su preceptiva intervención persigue garantizar a la parte una defensa técnica (STC 132/1992, de 28 de septiembre) evitando la indefensión. El TC ha a firmado, por consiguiente, la obligación que a los órganos jurisdiccionales corresponde de velar por la indefensión de los justiciables en el proceso.

A la asistencia hay que dotarla de la necesaria efectividad y eficacia, so pena de considerarlo un derecho vacío o meramente formal, pues nada es más lógico y natural que pensar que una adecuada defensa y asistencia letrada exige el previo requisito de una comunicación interpersonal inteligible e incluso fluida en asunto tan crucial como la trasmisión al abogado no solo de hechos, sino de vivencias y apreciaciones, por parte del acusado, y ante la perspectiva de su juicio oral, aparte de su colaboración para la propuesta de pruebas. Y esto

${ }^{26}$ El derecho a un juicio justo y equitativo exige la garantía del derecho al juez imparcial, habiendo establecido dicho Tribunal, como criterios para la determinación de un tribunal, no sólo el modo de designación, sino también la duración del mandato de sus miembros, la existencia de garantías contra presiones exteriores, y la apariencia o no de independencia (STEDH 547/2001). 
es tan evidente que se puede incluir con naturalidad, sin más esfuerzo integrado, en el haz de derechos que antes se ha indicado, concretamente el de disponer de las facultades necesarias para la preparación de la defensa del acusado.

Contenido esencial de la prohibición de indefensión es el derecho a utilizar los medios de prueba pertinentes. Esta garantía, complementaria de las anteriores en orden a la efectividad de la tutela judicial, parte de la importancia de la prueba para la defensa y da cumplimiento al mandato constitucional de prohibición de indefensión.

$\mathrm{El}$ art. 24.2 CE ha convertido en un derecho fundamental el derecho de utilizar los medios de prueba pertinentes en cualquier tipo de procesos en que el ciudadano se vea involucrado. Este derecho fundamental, inseparable del derecho mismo a la defensa, consiste en que las pruebas pertinentes sean admitidas y practicadas por el Juez o el Tribunal, y al haber sido constitucionalizado, impone una nueva perspectiva y una sensibilidad mayor en relación con las normas procesales atinentes a ello, de suerte que pueden los tribunales de Justicia proveer para la satisfacción de tal derecho, sin desconocerlo ni obstaculizarlo, siendo preferible en tal materia incurrir en un posible exceso en la admisión de pruebas que en su denegación.

Ello no implica, de conformidad con la doctrina constitucional., desapoderar al juzgador a quo de su potestad de pronunciarse sobre la pertinencia de las pruebas que las partes propongan, sino acoger, con el espíritu que informa el art. 24.2 CE, las peticiones de admisión a prueba en cuanto no sea manifiesta la ausencia de adecuación entre la que se propone y la cuestión debatida. Para prestar consistencia a una queja motivada en el indebido rechazo de un medio de prueba será, pues necesario que se argumente por el demandante en amparo la trascendencia de dicha inadmisión, por la relevancia misma de los hechos que así se quisieron probar, pudo tener en la sentencia condenatoria, ya que sólo en tal caso -comprobado que el fallo pudo, acaso, haber sido otro si la prueba se hubiera admitido- podrá apreciarse también el menoscabo efectivo del derecho de quien por este motivo buscar amparo (STC 30/1986, de 20 de febrero).

No comprende este derecho-garantía la facultad de realizar una prueba ilimitada, sino que atribuye el derecho a la recepción y práctica de las que sean pertinentes, constituyendo doctrina constitucional la necesidad de comprobación de si la falta de práctica de una prueba se deriva de una real y efectiva indefensión, y la necesidad de que el recurrente no haya incurrido en negligencia en el momento de impetrar la prueba realizada (STC 69/2001, de 17 de marzo). 
Tampoco protege frente a eventuales irregularidades $\mathrm{u}$ omisiones procesales en materia de prueba, sino frente a la efectiva y real indefensión que puede sufrirse con ocasión de esas irregularidades. La necesidad de prueba en el proceso es ciertamente algo contingente, pues puede ser superflua o la parte puede renunciar a ella, pero cuando el procesado la pida, este derecho significa que la parte tiene derecho a utilizar los medios de prueba para su defensa que considere oportunos, siempre que se asegure su veracidad y que la forma de obtenerlos haya cumplido con todos los requisitos legales y constitucionales, y cuando la prueba sea pertinente, en cuyo caso deberán ser admitidas y practicadas sin desconocimiento ni obstáculos (STC 183/2002, de 14 de octubre).

Este derecho tampoco faculta para exigir la admisión judicial de todas las pruebas que puedan proponer las partes, sino que atribuye sólo el derecho a la recepción y práctica de las que sean pertinentes, correspondiendo a los jueces y tribunales el examen sobre la legalidad y pertinencia de las pruebas, por lo que al Tribunal Constitucional solamente se le atribuye la competencia: a) para comprobar que la inadmisión de la prueba esté motivada y no incurra en manifiesta arbitrariedad o irrazonabilidad, y b) la inactividad judicial relevante o decisiva para el proceso una vez admitida, teniendo en consideración que para la acreditación o determinación de la relevancia de la prueba, habrá que demostrar, de un lado, la relación entre los hechos que se quisieron y no se pudieron probar y las pruebas inadmitidas, y, de otro, argumentar de modo convincente que la resolución final del proceso podría haberle sido favorable a una de las partes de haberse aceptado y practicado la prueba objeto de la controversia (STC 69/2001 de 17 de marzo, STC 147/2002 de 15 de julio).

La denegación arbitraria e injustificada del derecho a la prueba supone la indefensión del ciudadano implicado en un proceso, $\mathrm{y}$, por tanto, una denegación del derecho a la defensa judicial efectiva de sus intereses, aunque esta garantía constitucional comprendida en el art. 24.2 CE únicamente cubre aquellos supuestos en que la prueba es decisiva en términos de defensa. Por último debemos señalar -para dejar cerrado este punto- que la limitación del derecho consagrado en el art. 24.2 CE al servirse de las pruebas pertinentes para su defensa como un derecho constitucional no justifica su sacrificio a intereses indudablemente dignos de su tutela, pero de rango subordinado, como pueden ser la economía del proceso, la mayor celeridad de éste o la eficacia en la Administración de Justicia. Es exclusivamente el juicio sobre la pertinencia lo que debe ser medido y en el que, como hemos dicho muchas veces, ha de considerarse válida la 
decisión adoptada por los jueces a quo en tanto no se ofrezcan razones suficientes para destruirla en el proceso de amparo (STC 51/1985, de 10 de marzo).

Se produce indefensión, pues, cuando no funciona correctamente la naturaleza del órgano judicial, la asistencia adecuada, o el sistema de prueba.

Como hemos observado, el derecho de defensa es un elemento nuclear en la configuración del Estado de Derecho. No es posible construir un proceso justo si se elimina esencialmente el derecho de defensa, de forma que las posibles restricciones deben estar especialmente justificadas.

En un sistema democrático como el regulado en la Constitución española, el Poder judicial se legitima por la aplicación de la ley a la que está sujeto, y no por la simple imposición de sus potestades ${ }^{27}$. De manera que el Estado de Derecho se vulnera cuando el juez, con el pretexto de aplicación de la ley, actúa solo su propia subjetividad concretada en una forma particular de entender la cuestión a resolver, y prescindiendo de todos los métodos de interpretación admisibles en derecho, acoge un significado irracional de la norma, sustituyendo así el imperio de la ley por un acto contrario de mero voluntarismo. La superación del simple positivismo, que pudiera conducir a actuaciones materialmente injustas, resulta de la Constitución y, especialmente, de sus normas sobre derechos fundamentales, que constituyen al tiempo una guía interpretativa y un límite infranqueable ${ }^{28}$.

Estos planteamientos previos, determinan que, en la labor de control del TC, no le corresponde constatar el grado de acierto de la resolución judicial en la interpretación o aplicación de las normas o en la valoración de los hechos, salvo que se violara algún derecho fundamental sustantivo o se limitara el derecho de acceso a la jurisdicción. Tampoco le corresponde al TC el control de la mera legalidad, rectificar errores, equivocaciones o incorrecciones jurídicas, salvo que se violara alguna garantía constitucional, ni tampoco le corresponde al TC la apreciación de los hechos encausados, puesto que estas actividades corresponden en exclusiva a los órganos judiciales, y en caso contrario, el recurso de amparo se transformaría en una nueva instancia de revisión. Lo que le corresponde al máximo intér-

27 Vid. VILLACORTA MANCEBO, L., El pleno sometimiento a la Constitución y al resto del ordenamiento jurídico en la aplicación judicial del Derecho, Dikinson, Madrid, 2004.

28 STS 79/2012, de 9 de febrero; STS 101/2012, de 27 de febrero. 
prete de la Constitución es la defensa de los derechos fundamentales, y en esta labor, y en lo que al derecho a la tutela judicial se refiere, lo que corresponde al TC en su función control es el estudio externo del razonamiento y la aplicación de los cánones de arbitrariedad, irrazonabilidad y error patente, al objeto de evitar la indefensión.

La prohibición de indefensión implica un mandato y una obligación para los poderes públicos. Como ha indicado el TC (STC 48/1984 de 4 de abril), en el contexto del art. 24, la indefensión se caracteriza por suponer una privación o una limitación del derecho a la defensa que, si se produce por vía legislativa, sobrepasa el contenido esencial de los derechos prevenido en el art. $53 \mathrm{CE}$, y si se produce en virtud de concretos actos de los órganos jurisdiccionales entraña una mengua del derecho de intervenir en el proceso y del derecho de alegar y probar lo alegado.

Se establecen, por consiguiente, una serie de mandatos, que también se extienden al Poder Ejecutivo. El derecho a la tutela y la prohibición de indefensión impone la necesidad de diseñar y adoptar una adecuada política judicial por parte de nuestros gobernantes, de desarrollarla por el legislador, encargado de crear la ley, y por los órganos jurisdiccionales, competentes para interpretarla y aplicarla.

El deber de impartir justicia no constituye una obligación de la que estén exentas las propias partes y los demás poderes del Estado. En lo que a las partes respecta, el ejercicio de este derecho reclama la obligación de probidad y de moverse dentro del proceso con buena fe, sin suscitar falsas incidencias que provoquen el retraso de las sentencias o de su ejecución. Respecto a los demás poderes del Estado, se traduce en la obligación de incrementar notablemente el número de plantillas orgánicas, de dotar a la justicia de medios materiales y humanos suficientes, y de realizar en nuestros códigos las reformas oportunas. Como ha indicado el $\mathrm{TEDH}^{29}$ la aplicación del derecho a un proceso sin dilaciones indebidas al derecho a un proceso equitativo enunciado en el art. 6.1 del Convenio implica la obligación para los Estados miembros de organizar su sistema judicial de tal forma que los tribunales puedan cumplir con las exigencias del Convenio.

29 STEDH 389/2001, Apdo. 62. 